LINGUA, Vol. 14, No. 2, September 2017

p ISSN: 1979 9411; e ISSN: 2442 238X

Http://lingua.pusatbahasa.or.id; Email: presslingua@gmail.com

Center of Language and Culture Studies, Surakarta, Indonesia

A'ini, Qurratul. 2017. Gaya Bahasa dalam Penggalan Novel Pudarnya Pesona Cleopatra

Karya Habiburrahman El Zhirazy. Lingua (2017), 14(2): 285 294.

\title{
GAYA BAHASA DALAM PENGGALAN NOVEL PUDARNYA PESONA CLEOPATRA KARYA HABIBURRAHMAN EL-ZHIRAZY
}

\author{
Qurratul A'ini \\ Universitas Sebelas Maret, Surakarta \\ qurrotulain07@gmail.com
}

\begin{abstract}
This literary work analyzes the novel by Habiburrahman El-zhirazy entitled "Clearing the Fade of Cleopatra" that tells a figure who was obsessed with the beauty of Egyptian women. The desire was vanished because the character was mated by her parents. Using a stylistic approach, this study examined how dictions and the existing majesties in the novel fragments were applied. The source of data was a fragment of the novel "Clearing the Fade of Cleopatra", and the data were the lingual units in terms of words, phrases, clauses and sentences that contained thf figurative languages. The study revealed that in selecting the dictions the writer used Arabic, English and Javanese. The selection of diction is certainly not separated from the author's background. The figurative language included hyperbole, metaphor, paradox, allegory and personification. The hyperbolic was used more frequently than other figurative languages.
\end{abstract}

Keywords: novel, style, diction, figurative language.

Karya sastra adalah suatu bentuk seni yang didalamnya terdapat pesan yang akan disampaikan kepada penikmat sastra melalui kata-katanya. Karya sastra bisa dalam bentuk puisi, novel, puisi, drama, cerpen dll. Masing-masing karya sastra memiliki ciri khas sesuai dengan gaya penulisnya, dalam hal ini gaya bahasa sehingga dari gaya tersebut, karya sastra itu bisa dikenali oleh banyak orang. Gaya dalam arti luas dapat menggambarkan gaya bahasa pada zamannya dan gaya bahasa suatu negara (Satoto, 1995:6-37). Melalui karya sastra pembaca bisa mengetahui gaya bahasa dan juga secara lebih luas gambaran kehidupan pada zaman tersebut.

Gaya tersebut, lebih jauh dibahas dalam kajian stilistika. Stilistika adalah ilmu yang meneliti penggunaan bahasa dan gaya bahasa di dalam karya sastra (Sudjiman dalam munir, 2013:2). Secara umum, kajian stilistika mencakupi diksi atau pilihan kata, struktur kalimat, majas, pola, dll. Gaya yang diungkapkan oleh penulis melalui tulisannya tersebut merupakan perwujudan penggunaan bahasa oleh seorang penulis untuk mengemukakan gambaran, gagasan, pendapat, dan membuahkan efek tertentu bagi penanggapnya sebagaimana cara yang digunakannya (Aminuddin dalam Munir, 2013:3). Jadi, melalui karya sastra tersebut diharapkan bisa mengambil banyak pelajaran dan nilai moral kepada para pembacanya.

Pembicaraan stilistika tidak dapat dilepaskan dari linguistik atau ilmu bahasa. Bahkan, secara tegas Starcke (2010:2) menyatakan bahwa stilistika sebagai salah satu disiplin linguistik. Eksistensi linguistik dalam konteks stilistika itu seperti tampak pada 
LINGUA, Vol. 14, No. 2, September 2017

p ISSN: 1979 9411; e ISSN: 2442 238X

Http://lingua.pusatbahasa.or.id; Email: presslingua@gmail.com

Center of Language and Culture Studies, Surakarta, Indonesia

A'ini, Qurratul. 2017. Gaya Bahasa dalam Penggalan Novel Pudarnya Pesona Cleopatra

Karya Habiburrahman El Zhirazy. Lingua (2017), 14(2): 285 294.

pandangan beberapa pakar. Junus (1989:xvii) misalnya, memandang stilistika sebagai ilmu gabung (inter atau multidisiplin) antara linguistik dan ilmu sastra. Widdowson (1997:3) dan Sudjiman (1993:3) memandang stilistika sebagai kajian mengenai diskursus (wacana) kesastraan yang beranjak dari orientasi linguistik. Mcrae dan Clark (dalam Davies dan Elder, 2006:328) berpendapat bahwa stilistika sebagai penggunaan linguistik (ilmu bahasa) untuk mendekati teks sastra.

Berdasarkan pandangan beberapa pakar tadi, dapat ditarik sebuah kesimpulan bahwa stilistika merupakan pengkajian sastra dari perspektif linguistik. Beberapa pandangan pakar di atas menjelaskan bahwa dasar pemahaman linguistik menjadi kebutuhan mutlak jika ingin menerapkan teori stilistika. Wellek dan Warren (1989:221) lebih menegaskan bahwa stilistika tidak dapat diterapkan dengan baik tanpa dasar linguistik yang kuat karena salah satu penelitian utamanya adalah kontras sistem bahasa karya sastra dengan penggunaan bahasa pada zamannya.

Stilistika tidak hanya merupakan studi gaya bahasa dalam kesusastraan saja, tetapi juga studi gaya dalam bahasa pada umumnya meskipun ada perhatian khusus pada bahasa kesusastraan yang paling sadar dan paling kompleks. Slamet Muljana (dalam Pradopo, 1993:2) mengemukakan bahwa stilistika itu pengetahuan tentang kata berjiwa. Kata berjiwa itu adalah kata yang dipergunakan dalam cipta sastra yang mengandung perasaan pengarangnya. Stilistika berguna untuk membeberkan kesan pemakaian susun kata dalam kalimat yang menyebabkan gayakalimat, disamping ketepatan pemilihan kata, memegang peranan penting dalam ciptaan sastra.

Stilistika adalah ilmu yang meneliti penggunaan bahasa dan gaya bahasa di dalam karya sastra. Stilistika merupakan sebuah proses dalam menganalisis karya sastra dengan melihat bagaimana unsur-unsur bahasa sebagai medium karya sastra digunakan sastrawan sehingga terlihat bagaimana perlakuan sasstrawan terhadap bahasa dalam rangka menuangkan gagasannya. Oleh sebab itu, semua proses yang berhubungan dengan analisis bahasa karya sastra dimaksudkan untuk mengungkapkan aspek kebahasaan dalam karya tersebut, seperti diksi, penggunaan bahasa kias, bahasa figuratif, struktur kalimat, bentuk-bentuk wacana, dan sarana retorika lainnya.

Dalam makalah ini yang menjadi objek kajiannya adalah karya sastra cerpen yang berjudul "pudarnya pesona cleopatra" karya Habiburrahman El Shirazy. Dalam cerpen tersebut akan dianalisis gaya bahasa yang digunakan oleh pengarang yaitu diksi dan majas sehingga dari gaya bahasa yang dipilih oleh pengarang tersebut nilai moral yang terdapat didalamnya bisa tersampaikan dengan baik kepada pembaca. Cerpen karya Habiburrahman ini tentunya tak lepas dari sisi kehidupan pengarangnya, baik latar belakang kehidupan maupun pendidikan sehingga gaya bahasa yang dipakai didalamnya bisa mencerminkan hal itu. Dengan demikian, rumusan masalah pada penelitian ini yaitu (1) Bagaimana diksi yang digunakan dalam cerita "Pudarnya Pesona Cleopatra" karya Habiburrahman El Shirazy? (2) Bagaimana penggunaan majas yang terdapat dalam "Pudarnya Pesona Cleopatra" karya Habiburrahman El Shirazy?. Tujuan penelitian yaitu untuk menjawab persoalan dari rumusan masalah (1) untuk mengetahui penggunaan diksi yang terdapat cerita "Pudarnya Pesona Cleopatra" karya Habiburrahman El Shirazy, (2) Untuk mengetahui majas yang digunakan dalam "Pudarnya Pesona Cleopatra" karya Habiburrahman El Shirazy. 


\section{METODE}

Pada analisis cerpen ini, pendekatan yang digunakan adalah pendekatan stilistika yang difokuskan pada diksi dan majas dalam cerpen. Adapun sumber datanya berupa penggalan novel, tidak keseluruhan isi novel. Judul novel "Pudarnya Pesona Cleopatra", sedangkan data dalam penelitian ini adalah satuan lingual yang berupa katakata, frasa, klausa dan kalimat dalam penggalan novel karya Habiburrahman El Shirazy tersebut. Jenis penelitiannya yaitu deskriptif kualitatif.

Jenis kajian dengan deskriptif kualitatif ini menekankan pada proses analisis induktif. Disebut induktif karena kualitatif tidak mengalisis data setelah beberapa waktu pengumpulan data. Sebaliknya, analisis penelitian kualitatif, tipe ini dilakukan setiap kali menemukan data (Lincoln \& Guba, 1985 dalam Santosa, 2012). Maka dari itu, penelitian ini tidak menggunakan hipotesis sebagai jawaban sementara terhadap permasalahan penelitian sebagaimana lazim dilakukan dalam penelitian kuantitatif.

\section{HASIL DAN BAHASAN}

Berdasarkan penelitian pada teks penggalan novel yang berjudul "Pudarnya pesona Cleopatra" diketahui penggunaan diksi dan majas didalamnya. Diksi yang digunakan didalamnya memanfaatkan penggunaan bahasa jawa, bahasa arab dan bahasa inggris. Pemanfaatan tersebut tentunya memiliki fungsi yang berbeda. Namun, pada hakikatnya diksi yang digunakan tak lepas dari konteks cerita dalam novel tersebut.

\section{Pemanfaatan Kosakata Bahasa Arab}

Di dalam cerpen karya Habiburrahman ini, terdapat beberapa diksi (pilihan kata) yang menggunakan bahasa arab diantaranya:

a. khitbah (lamaran)

Kata khitbah terdapat dalam cerpen tersebut untuk menjelaskan makna hukum agama Islam yang lebih dalam mengenai proses melamar. Diksi tersebut dipilih agar bisa mendukung tokoh yang ada dalam cerpen. Tokoh laki- laki dalam cerpen adalah lulusan mesir, sedangkan tokoh perempuan (Raihana) adalah lulusan pondok pesantren. Dengan demikian, untuk pemilihan diksi "khitbah" sangat mendukung dalam penggunaannya yang untuk mendukung konteks cerita.

\section{b. Rabbighfir li wa liwalidayya!}

Diksi yang kedua merupakan lafal bahasa arab yang artinya ampunilah dan kasihilah. Satuan lingual tersebut merujuk kepada seorang ibu dari tokoh aku dalam cerpen. Tokoh aku mendoakan ibunya karena ia merasa sangat menyayanginya namun disisi lain ia tidak bisa menerima permintaan ibunya dengan tulus.

\section{c. wallahu a'lam}

Diksi yang selanjutnya yaitu "wallahu a'lam" merupakan frasa yang memiliki maksud untuk mengungkapkan bahwa Allah yang maha mengetahui. 
Hal ini diucapkan oleh tokoh utama dalam novel (aku) kepada istrinya (Raihana) atas keraguan perasaannya.

d. InsyaAllah

Selanjutnya yaitu pemilihan kata "insyaAllah" merupakan kata untuk mengungkapkan kebesaran Allah yang artinya "jika Allah menghendaki".

e. Santriwati

Kata "santriwati adalah kata yang memiliki arti siswa perempuan dalam pondok pesantren. Siswa perempuan yang sekolah/ mencari ilmu di pesantren, bisa dijuluki santriwati. Diksi itu dipilih karena tokoh kedua (Raihana) dalam cerpen merupakan lulusan pondok pesantren yang hafal Alquran.

\section{f. Alhamdulillah}

Pilihan kata yang selanjutnya yang terdapat pada cepen yaitu "Alhamdulillah". Ini merupakan ungkapan syukur yang memiliki arti segala puji bagi Allah.

\section{g. Predikat jayyid}

Kata selanjutnya yaitu "predikat jayyid", kata tersebut memiliki arti predikat yang bagus. Hal itu diungkap oleh teman dari tokoh pertama tentang predikat lulusnya sewaktu kuliah di Mesir. Ini sangat mendukung konteks karena ia lulusan dari universitas di Mesir, yang tentu bahasa kesehariannya adalah bahasa Arab.

h. Rabbi

Kata "Rabbi" adalah diksi yang juga terdapat pada cerpen ini. dalam bahasa arab "Rabbi" memiliki arti Tuhanku, yaitu Allah. Kata tersebut digunakan dalam cerpen saat tokohnya berdoa dan berseru kepada Allah.

\section{i. Lakal hamdu ya rabb}

Diksi yang selanjutnya yaitu "Lakal hamdu ya rabb" memiliki arti segala puji bagimu ya Tuhan. Merupakan ungkapan rasa syukur dalam bahasa Arab selain kata Alhamdulillah.

\section{Pemanfaatan Kosakata Bahasa Inggris}

Untuk pemanfaatan bahasa inggris diketahui ada dua yaitu (a) baby face (b) enjoy. Untuk satuan lingual yang pertama yaitu baby face, merupakan satuan lingual untuk mengungkap keadaan fisik tokoh kedua yaitu Raihana yang memiliki wajah tampak muda dan cantik. Diksi yang kedua yaitu "enjoy" merupakan ungkapan keadaan yang terdapat dalam konteks cerita yang diungkapkan oleh tokoh dalam cerita. Satuan lingual yang menggunakan bahasa inggris itu bertujuan untuk membawa alur cerita lebih ringan dibaca oleh pembaca karena kata-kata tersebut sudah sangat populer digunakan dalam percakapan sehari-hari. 


\section{Pemanfaatan Kosakata Bahasa Jawa}

Pemilihan kata yang menggunakan bahasa jawa hanya ditemukan satu, yaitu "Wedang jahe". Wedang adalah bahasa jawa yang artinya minuman hangat, sedangkan wedang jahe adalah minuman hangat yang dicampur jahe. Minuman ini biasanya diminum untuk menghangatkan badan. Konteks cerita dalam cerpen menceritakan tokoh pertama yang sedang sakit, diperkirakan masuk angin sehingga ia meminum wedang jahe untuk meredakan sakitnya.

Diksi-diksi yang digunakan dalam novel tersebut dengan memanfaatkan bahasa arab, inggris dan jawa memiliki fungsi mengintensifkan makna dan menguatkan latar tokoh. Dalam cerita tersebut, tokohnya adalah orang-orang yang beragama Islam, lulusan mesir dan belajar dipesantren sehingga bahasa arab dipilih untuk diksi tertentu. sedangkan bahasa Inggris juga demikian adanya, karena tokoh dalam cerita adalah orang terpelajar dan pandai dalam keilmuan, maka ada beberapa kata yang memanfaatkan bahasa inggris. Dan terakhir adalah bahasa jawa, tokoh pertama dalam novel memiliki seorang ibu yang pernah mondok/ menempuh ilmu di salah satu pesantren di Solo, sehingga penulis menggunakan bahasa jawa dalam diksi tertentu.

Selebihnya, jika dipandang dari latar belakang penulis, ia adalah novelis terkenal dan merupakan orang yang ahli dalam bidang agama. Ia pernah menempuh pendidikan di Mesir dan pernah belajar di Pondok Pesantren, sehingga gaya bahasa dalam penulisannya juga kebanyakan menyisipkan bahasa arab dan semua karyanya bernada religius.

\section{Penggunaan Majas}

Selain diksi (pilihan kata), dalam cerpen karya Habiburrahman ini juga menggunakan beberapa majas dalam pengungkapan bahasanya, diantaranya majas hiperbola, metafora, paradoks, alegori dan personifikasi. Majas yang paling banyak digunakan dalam cerpen ini adalah majas hiperbola. Hiperbola adalah majas yang berupa pernyataan berlebihan dari kenyataannya dengan maksud memberikan kesan mendalam atau meminta perhatian. Hal ini menjadikan cerita dalam cerpen lebih mendalam maknanya bagi pembaca. Beberapa majas hiperbola yang terdapat dalam cerita di antaranya:

1) Dengan panjang lebar ibu menjelaskan

2) Dalam pergulatan jiwa yang sulit berhari-hari

3) Namun garis-garis kecantikan yang kuinginkan tak kutemukan sama sekali

4)Tapi penilaianku lain, mungkin karena aku begitu hanyut dengan gadis-gadis Mesir titisan Cleopatra, yang tinggi semampai, wajahnya putih jelita, dengan hidung melengkung indah, mata bulat bening khas arab, dan bibir yang merah.

5) aku berusaha menumbuhkan bibit-bibit cintaku untuk calon istriku

6) kumohon bukalah sedikit hatimu untuk menjadi ruang bagi pengabdianku, bagi menyempurnakan ibadahku didunia ini

7) Sang ratu mempersilakan aku duduk di kursi yang berhias berlian 
8) Suara lembut Raihana menyadarkan pengembaraanku pada Jaman Ibnu Hazm

9) Matanya sedikit berbinar

10) Raihana menatapku dengan wajah sangat cerah, ada secercah senyum bersinar dibibirnya

11) Aku memaki- maki diriku sendiri atas sikap dinginku selama ini.Tapi, setetes embun cinta yang kuharapkan membasahi hatiku tak juga turun

12) Wajah Raihana cerah. Matanya berbinar-binar bahagia

13) Rasa cinta yang dari detik ke detik meneteskan rasa bahagia

14) Namun hatiku menangis karena cinta tak kunjung tiba

15) Puncak penderitaan saya dimulai setahun yang lalu

16) Dibawah kasur itu kutemukan kertas Merah jambu. Hatiku berdesir, darahku terkesiap

17) Ia menulis, betapa ia mati-matian mencintaiku, meredam rindunya akan belaianku. Ia menguatkan diri untuk menahan nestapa dan derita yang luar biasa

18) Wajahnya yang baby face dan teduh, pengorbanan dan pengabdiannya yang tiada putusnya, suaranya yang lembut, tanganya yang halus bersimpuh memeluk kakiku, semuanya terbayang mengalirkan perasaan haru dan cinta. Dalam keharuan terasa ada angin sejuk yang turun dari langit dan merasuk dalam jiwaku

19) Cahaya Raihana terus berkilat-kilat dimata

20) Hatiku pilu. Jiwaku remuk.

Majas metafora adalah majas yang mengungkapkan ungkapan secara langsung berupa perbandingan analogis. Dalam cerpen majas metafora yang ditemukan ada 2 . Dengan majas metafora tersebut, cerpen ini membawa imajinasi pembaca yang kaitannya dengan logika sehingga maksud penulis bisa tersampaikan kepada pembaca. Majas metafora yang terdapat di dalam cerpen di antarnya:

1) Aku ingin menjadi mentari pagi di hatinya

2) cantiknya alami, bisa jadi bintang iklan Lux lho, asli!.

Selain dua majas di atas, majas paradoks juga ditemukan dalam novel. Majas paradoks adalah majas yang mengandung pertentangan antara pernyataan dan fakta. Dengan majas ini penulis mengajak pembaca untuk membandingkan sehingga pesan dan kesan bisa sampai kepada pembaca. Beberapa majas paradoks yaitu:

1) Dengan hati pahit kuserahkan semuanya bulat-bulat pada ibu

2) Aku ingin memberontak pada ibuku, tetapi wajah teduhnya meluluhkanku

3) Suaranya yang lembut terasa hambar, wajahnya yang teduh tetap terasa asing

4) Meskipun hatiku belum terbuka lebar, tetapi wajah Raihana telah menyala di dindingnya 
LINGUA, Vol. 14, No. 2, September 2017

p ISSN: 1979 9411; e ISSN: 2442 238X

Http://lingua.pusatbahasa.or.id; Email:presslingua@gmail.com

Center of Language and Culture Studies, Surakarta, Indonesia

A'ini, Qurratul. 2017. Gaya Bahasa dalam Penggalan Novel Pudarnya Pesona Cleopatra

Karya Habiburrahman El Zhirazy. Lingua (2017), 14(2): 285 294.

Di dalam cerita tersebut juga terdapat majas alegori dan personifikasi. Majas alegori dan personifikasi merupakan majas perbandingan dengan perbedaan masingmasing. Majas alegori adalah menyatakan dengan cara lain, melalui kiasan atau penggambaran, sedangkan personifikasi adalah majas yang membandingkan bendabenda tak bernyawa seolah-olah mempunyai sifat seperti manusia. Dengan seperti itu, apa yang digambarkan penulis membuat pembaca ingin terus membaca karena bahasa yang digunakan menggunakan gaya-gaya yang disamakan dengan benda hidup. Lebih dari itu, cerita akan lebih hidup jika hal-hal semacam itu ada dalam cerita. Beberapa majas alegori di antaranya:

1) Duduk di pelaminan bagai mayat hidup

2) Jika ada sedikit letupan, maka rumah seperti neraka

3) Kata Yasmin yang bagaikan geledek menyambar.

Dan yang terakhir, majas yang ada terdapat dalam cerpen yaitu majas personifikasi yaitu (1) Hari terus berjalan, tetapi komunikasi kami tidak berjalan. Secara spesifik, klasifikasi penggunaan majas dapat dilihat pada tabel 1.

Tabel 1. Klasifikasi Penggunaan Jenis Majas

\begin{tabular}{|c|c|c|c|c|c|c|}
\hline \multirow{2}{*}{ NO } & \multirow{2}{*}{ SATUAN LINGUAL DALAM CERPEN } & \multicolumn{5}{|c|}{ JENIS MAJAS } \\
\hline & & HPB & MTF & PRD & ALG & PRN \\
\hline 1. & Dengan panjang lebar ibu menjelaskan. & & & & & \\
\hline 2. & Dalam pergulatan jiwa yang sulit berhari-hari. & & & & & \\
\hline 3. & $\begin{array}{l}\text { Namun garis-garis kecantikan yang } \\
\text { kuinginkan tak kutemukan sama sekali. }\end{array}$ & & & & & \\
\hline 4. & $\begin{array}{l}\text { Tapi penilaianku lain, mungkin karena aku begitu } \\
\text { hanyut dengan gadis-gadis Mesir titisan } \\
\text { Cleopatra, yang tinggi semampai, wajahnya putih } \\
\text { jelita, dengan hidung melengkung indah, mata } \\
\text { bulat bening khas arab, dan bibir yang } \\
\text { merah. }\end{array}$ & & & & & \\
\hline 5. & $\begin{array}{l}\text { Aku berusaha menumbuhkan bibit-bibit } \\
\text { cintaku untuk calon istriku. }\end{array}$ & & & & & \\
\hline 6. & $\begin{array}{l}\text { Kumohon bukalah sedikit hatimu untuk menjadi } \\
\text { ruang bagi pengabdianku, bagi menyempurnakan } \\
\text { ibadahku didunia ini. }\end{array}$ & & & & & \\
\hline 7. & $\begin{array}{l}\text { Sang ratu mempersilakan aku duduk di kursi } \\
\text { yang berhias berlian }\end{array}$ & & & & & \\
\hline 8. & $\begin{array}{l}\text { Suara lembut Raihana menyadarkan } \\
\text { pengembaraanku pada Jaman Ibnu Hazm. }\end{array}$ & & & & & \\
\hline 9. & Matanya sedikit berbinar. & & & & & \\
\hline 10. & $\begin{array}{l}\text { Raihana menatapku dengan wajah sangat cerah, } \\
\text { ada secercah senyum bersinar dibibirnya. }\end{array}$ & & & & & \\
\hline 11. & $\begin{array}{l}\text { Aku memaki- maki diriku sendiri atas sikap } \\
\text { dinginku selama ini.Tapi, setetes embun cinta } \\
\text { yang kuharapkan membasahi hatiku tak juga } \\
\text { turun. }\end{array}$ & & & & & \\
\hline
\end{tabular}


LINGUA, Vol. 14, No. 2, September 2017

p ISSN: 1979 9411; e -ISSN: 2442 238X

Http://lingua.pusatbahasa.or.id; Email:presslingua@gmail.com

Center of Language and Culture Studies, Surakarta, Indonesia

A'ini, Qurratul. 2017. Gaya Bahasa dalam Penggalan Novel Pudarnya Pesona Cleopatra

Karya Habiburrahman El-Zhirazy. Lingua (2017), 14(2): 285 294.

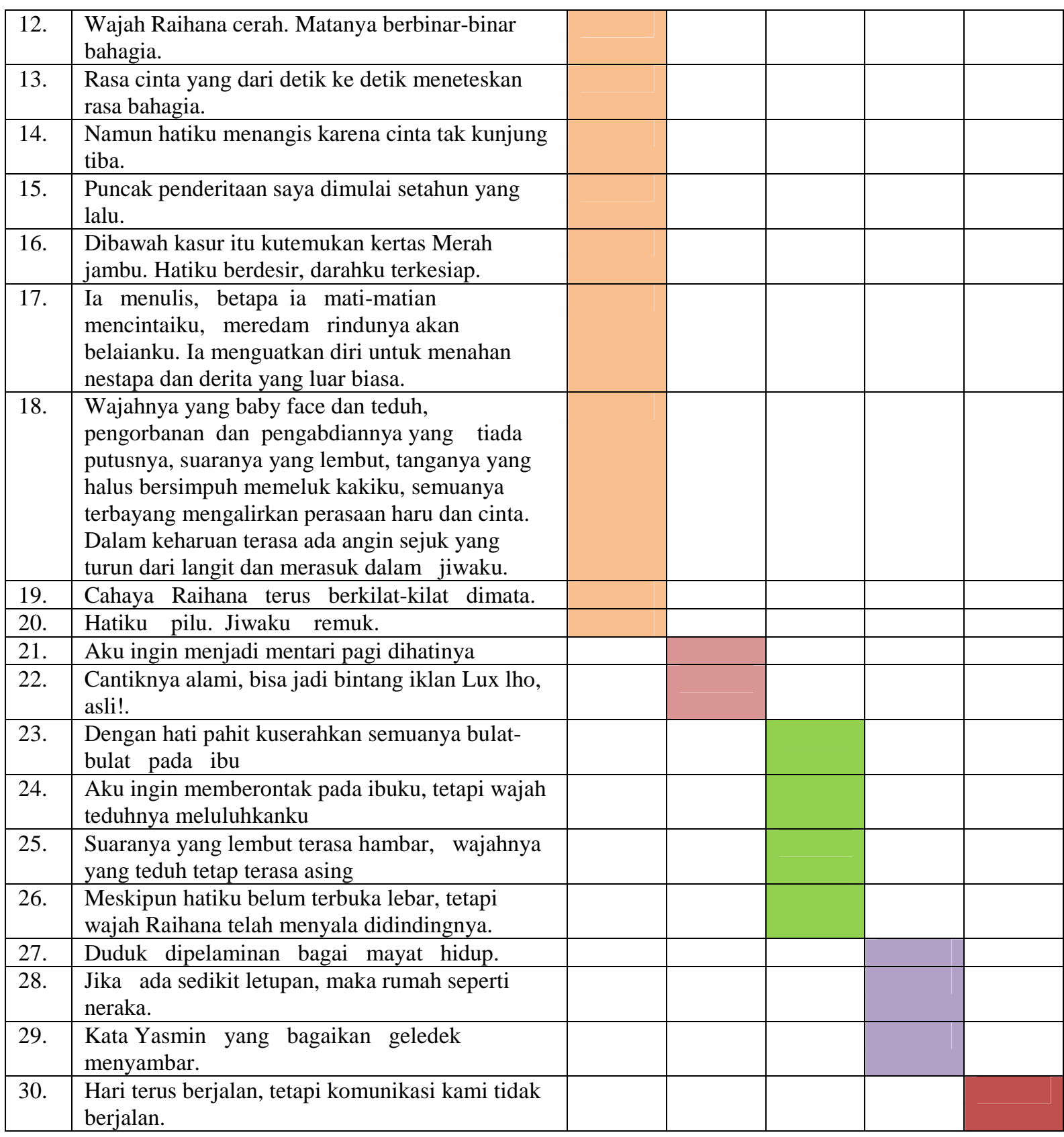

Ket : HPB : Hiperbola

MTF : Metafora

PRD : Paradoks

ALG : Alegori

PRN : Personifikasi 


\section{SIMPULAN}

Di dalam penggalan novel karya Habiburrahman El-Shirazy yang berjudul "Pudarnya Pesona Cleopatra", penulis menggunakan beberapa pilihan diksi dan majas agar cerita semakin menarik. Diksi tersebut di antaranya dengan memanfaatkan kosakata Bahasa Arab, memanfaatkan kosakata Bahasa Inggris dan memanfaatkan kosakata Bahasa Jawa. Penggunaan majas juga digunakan oleh penulis untuk menjadikan cerpen lebih hidup. Pemilihan diksi yang digunakan oleh penulis bertujuan untuk menjadikan cerita lebih hidup dengan melihat setting, latar belakang, dan alur cerita. Lebih dari itu, pemilihan diksi juga tak lepas dari latar belakang penulis baik dari sisi pendidikan dan kehidupannya. Majas yang terdapat dalam cerpen diantaranya hiperbola, metafora, paradoks, alegori dan personifikasi. Majas hiperbola adalah majas terbanyak yang ditemukan dalam cerpen yaitu berjumlah 20. Selanjutnya majas metafora ditemukan sebanyak 2, majas paradoks sebanyak 4, majas alegori 3 dan majas personifikasi sebanyak 1 .

\section{DAFTAR PUSTAKA}

Davies, Alan and Catherine Elder (Ed). 2006. The Handbook of Applied Linguistics. Australia: Blackwell Publishing.

El- Shirazy, Habiburrahman. 2005. Pudarnya Pesona Cleopatra (Sebuah Novel Pembangun Jiwa). Jakarta: Republika.

Junus, Umar. 1989. Stilistika: Satu Pengantar. Kuala Lumpur: Dewan Bahasa dan Pustaka.

Munir, saiful, dkk. 2013. Diksi dan Majas dalam Kumpulan Puisi Nyanyian Kelam Karya Sutikno WS: Kajian Stilistika. UNNES

Pradopo, Rachmad Joko. 1993. Stilistika (Artikel). Surakarta.

Satoto, Soediro. 1995. Stilistika. Surakarta: Institur Seni Indonesia Press

Starcke, Bettina Fischer. 2010. Corpus Linguistics in Literary Analysis. New York: Continuum International Publishing Group.

Sudjiman, Panuti. 1993. Bunga Rampai Stilistika. Jakarta: Pustaka Utama Grafiti.

Wellek, Rene dan Austin Warren. 1989. Teori Kesusastraan. Diterjemahkan oleh Melani Budianta. Jakarta: Gramedia.

Widdowson, H.G. 1997. Stilistika dan Pengajaran Sastra. Diterjemahkan oleh Sudijah. Surabaya: Airlangga University Press. 
LINGUA, Vol. 14, No. 2, September 2017

p ISSN: 1979 9411; e ISSN: 2442 238X

Http://lingua.pusatbahasa.or.id; Email:presslingua@gmail.com

Center of Language and Culture Studies, Surakarta, Indonesia

A'ini, Qurratul. 2017. Gaya Bahasa dalam Penggalan Novel Pudarnya Pesona Cleopatra

Karya Habiburrahman El Zhirazy. Lingua (2017), 14(2): 285 294. 